\title{
Scientists need back-up by climate organizations
}

SIR - George Monbiot and the other authors of the Correspondence letter ${ }^{\alpha}$ Time to speak up for climate-change science" (Nature 434, $559 ; 2005$ ) call on climate scientists to defend the scientific state of knowledge in public debate.

However, more is needed than just to speak out in the media. To spread scientific knowledge effectively, the science community must engage in a dialogue with policy-makers, federal agencies and the private sector.

For single scientists this task may be too time-consuming, on top of their research and teaching activities. Appropriate structures, dosely linked to the science community and enjoying high credibility, are needed to support them in this task.

In Switzerland, such structures have been in existence for more than ten years. ProClim (www.proclim.ch), a forum run by the Swiss
Academy of Sciences, and the academy's Advisory Body on Climate Change (OcCC) actively follow the public debate, selecting important issues and working with the science community to prepare assessments (see for example, Extreme Events and Climate Change 2003; www. occc.ch/ reports_e.html). ProClim maintains a valuable database of Swiss climate and global-change experts, which allows it to issue position papers and comments for the public debate, reducing the effort for individual scientists.

The work of ProClim and the OcCC is widely accepted. Swiss ministers and parliamentary committees regularly ask for direct advice and consult scientists contacted through this office. But this service costs money: it is funded through the Swiss Academy of Sciences and by the Swiss government.
Similar organizations exist in some other countries - for example the German Advisory Council for Global Change (www.wbgu.de) and the Austrian Climate Portal (www.accc. at) - but not everywhere in Europe.

We, and colleagues at other Swiss universities and institutes, consider that such offices, in addition to independent organizations such as www.realclimate.org, provide an efficient way for science to enter into a dialogue with the public and policy-makers.

Christian Körner*, Heinz Wannert, Christoph Ritzł

*Institute of Botany, University of Basel, Schōnbeinstrasse 6, CH-4056 Basel, Switzerland †Institute of Geography, University of Bem, Hallerstrasse 12, CH-3012 Bern, Switzerland $\ddagger$ ProClim, Swiss Acaderny of Sciences, Schwarztorstrasse 9, CH-3007 Bern, Switzerland

\section{Love of nature led Beuys to new artistic language}

SIR - As a geneticist-turned-artist, I enjoyed Martin Kemp's Science in Culture artide on the German artist Joseph Beuys, "The Pied Piper of Dïsseldorf" (Nature $434,141 ; 2005)$. However, I believe that Beuys' relationship with the sciences goes even deeper than portrayed here.

Beuys was always a great lover of animals and plants, and not just as a youth. His expertise in herbs and spices made him a great chef. During the war years, Beuys was close to a superior officer, Heinz Sielmann, also a naturalist. Although Beuys gave up ideas of medical training quite early on, he continued to develop his knowledge of natural history through Sielmann. It is through him that Beuys met Konrad Lorenz, who had established a comparative-ethology department at the Max Planck Institute of Buldern, Westphalia, in 1950.

These contacts gave Beuys a profound respect for nature, both biological and physical. This may be seen in two distinct aspects of his work. One aspect involved a series of specially chosen animals - the hare, the swan, the bee, the stag, the coyote - which existed for Beuys as metaphors for a kind of biological organization that seemed to him to offer a real source of reflection for mankind (as in Honey Pump in the Workplace, 1977). Many of the drawings in The Secret Block for a Secret Person in Ireland (1936-76) make reference to these animals, which belong, according to Beuys, to both mythology and natural science.

The other aspect of Beuys' sculptural work invoked the phenomena of heat and electricity. Beuys did not use these phenomena in a strictly scientific sense, but he went beyond a purely sculptural use of these materials. Thus copper, felt, grease (which could itself melt during an installation) all contribute to the 'experience' of the exhibited art-object. Beuys' idea of potential electric energy, for example, is revealed in the series Fond VII/2 (1967-84) through piles of cut and layered felt that rise $80 \mathrm{~cm}$ to $150 \mathrm{~cm}$ above the ground, linked by frail copper wiring that gives the visitor a sense of what stored (potential) energy might 'look like.'

My own work on a web-based sci-art project called "invisible" (www.invisiblecities.com) leads me to believe that one cannot easily divide Western culture into art on the one hand and science on the other.

Rather than seeing Beuys' contribution as part of a long history of utopian visions, I personally believe that Beuys developed a language through plastic form which, although not wholly reducible to natural science, was not wholly reducible to art either. As such, Beuys is to be congratulated.

Pete Jeffs

83 nue de Bagnolet, Paris 75020, France

\section{Head of Lorenz Institute is not to blame for delays}

SIR - The members of the advisory board of the Konrad Lorenz Institute for Ethology in Vienna were surprised by erroneous statements in your News story ${ }^{\alpha}$ Viennese lab renovations stall as cash goes unspent ${ }^{\text {” }}$ (Nature 434, 550; 2005). The reader is left
"My own work on a web-based sci-art project called "invisible" leads me to believe that one cannot easily divide Western culture into art on the one hand and science on the other." - Pete Jeffs

with the wrong impression that a substantial proportion of the advisory board's membership is critical both of the work of Dustin Penn as its director and of the allocation of the institute's finances.

As chair of the board, I feel obliged to clearly state, in the name of the board, that its members fully support Penn and his research plans.

It is correct that renovations and construction of facilities are needed. However, Penn is in no way to be blamed for the delay of these activities, which have turned out to be much more difficult than could have been anticipated.

The board is also aware of unspent money. However, this money has been put aside for investments needed when the new facilities are completed.

Friedrich G. Barth

Department of Neurobiology and BehaviouralSciences, Faculty of Life Sciences, University of Vienna, Institute of Zoology, Althanstrasse 14, A-1090 Vienna, Austria

Nature has learned from several sources that the board of the Konrad Lorenz Institute is not unanimous in its support for the work of its director. Nature therefore stands by the content of this News story - Editor, Nature. 